\title{
LA CONSTITUCIÓN ARGENTINA Y LAS DECISIONES DE ORGANISMOS SUPRANACIONALES ${ }^{*}$
}

Argentina's Constitution And the DeCisions of SUPRANATIONAL BODIES

La Constitution de l’Argentine eT Les déCisions

DES AGENCES SUPRANATIONALES

Martín J. ACEVEdo-Miño**

La Constitución de la Nación Argentina, en su redacción original y que se conserva hasta el momento, establece que "el Gobierno federal está obligado a afianzar sus relaciones de paz y comercio con las potencias extranjeras por medio de tratados que estén en conformidad con los principios de derecho público establecidos en esta Constitución". Pero en este contexto cabe recordar, además, que la incorporación de tratados internacionales con jerarquía constitucional en el artículo 75 inciso 22 del texto con la reforma de 1994 no implicó la derogación del referido artículo. Por el contrario, el propio texto fue preciso al aclarar que dichos instrumentos sobre derechos humanos "no derogan artículo alguno de la primera parte de esta Constitución y deben entenderse complementarios de los derechos y garantías por ella reconocidos". Pero algunas dudas se suscitan al momento de aplicar en el orden interno disposiciones de organismos jurisdiccionales supranacionales, precisamente en virtud de los tratados antes referidos.

Desde el recordado caso "Almonacid Arellano y otros vs. Chile" ${ }^{2}$, la Corte Interamericana de Derechos Humanos ha establecido el llamado "control de convencionalidad", como obligación de los Estados parte del sistema de invalidar las normas internas que se contrapongan a la Convención Americana sobre Derechos Humanos. Esa declaración sobre la convencionalidad o no de una norma, que será llevada a cabo por los jueces de cada Estado, podrá serlo aun de oficio, de acuerdo a la doctrina del referido tribunal, que se esbozó en "Myrna Mack Chang vs. Gua-

\footnotetext{
*El artículo fue aprobado para su publicación el 10 de junio de 2013.

${ }^{*}$ Abogado de la Universidad Católica de Santa Fe, Argentina. Curso de Postgrado en Derecho Constitucional de la Universidad de Salamanca. Profesor de Derecho Constitucional de la Pontificia Universidad Católica Argentina. Director del Departamento de Derecho de la Facultad Teresa de Ávila de la Pontificia Universidad Católica Argentina. Ex diputado constituyente provincial. Correo electrónico acevedomino@ fibertel.com.ar.

${ }^{1}$ Artículo 27 Constitución Nacional.

${ }^{2} \mathrm{CIDH}, 26$ de septiembre de 2006.
} 
temala" (25 de noviembre de 2003) y se consolidó en "Trabajadores Cesados del Congreso (Aguado Alfaro y otros) vs. Perú" (24 de noviembre de 2006).

La constitucionalista argentina María Angélica Gelli plantea, en un trabajo sobre el seguimiento de los criterios de la Corte Interamericana en los pronunciamientos de la Corte Suprema, que "la expresión 'no derogan artículo alguno de la Constitución' fue interpretada por la mayoría de la Corte Suprema en varios precedentes, en el sentido de que las Convenciones de Derechos Humanos no habían derogado ningún artículo de la Constitución Nacional porque los convencionales constituyentes de 1994, al declarar la jerarquía constitucional de esos tratados habían efectuado el juicio de comprobación de la compatibilidad entre Tratados y Constitución" 3 . Agregando que "esta compatibilidad que se presupone en la doctrina mayoritaria de la Corte Suprema, no se extiende a la jurisprudencia internacional, si no es pasándola por el tamiz de la interpretación judicial en el orden interno".

Pareciera entonces que, en palabras de LinAREs QuintANA, "la interpretación de las disposiciones constitucionales constituye uno de los más importantes problemas en el campo del derecho constitucional [ya que t] oda cuestión constitucional depende, en última instancia, de la interpretación de la Constitución” ". Según Ferrer Mac Gregor ${ }^{5}$, con el surgimiento de la normativa supranacional han surgido también diversos criterios para resolver los conflictos entre la normativa interna y la internacional, advirtiendo que la tendencia en América Latina se encamina hacia que sea el derecho constitucional interno el que resuelva la problemática. Calificada doctrina argentina ha advertido que "tanto los judicantes nacionales como los de la Corte IDH deben buscar la 'compatibilidad' entre las normas locales... y las reglas de los demás instrumentos internacionales a los que el país ha adherido, Tratados, Convenciones, Resoluciones, Declaraciones, Informes, etc., tales como el Protocolo de San Salvador; el Protocolo relativo a la Abolición de la Pena de Muerte; la Convención para Prevenir y Sancionar la Tortura; la Convención de Belem do Pará para la Erradicación de la Violencia contra la Mujer; la Convención sobre Desaparición Forzada; etcétera; que integran el corpus iuris convencional de los derechos humanos. Para esto también se debe tener en cuenta la 'jurisprudencia' de la Corte regional"'.

\footnotetext{
${ }^{3}$ GelLi, María Angélica (2010). "El valor de la jurisprudencia internacional. A propósito del caso 'Bayarri' en un dictamen de la Procuración General de la Nación”. Diario La Ley, Suplemento de Derecho Constitucional, $1^{\circ}$ de junio.

${ }^{4}$ Linares Quintana, Segundo (1998). Tratado de Interpretación Constitucional. Documento Lexis No $2102 / 000468$.

${ }^{5}$ Ferrer Mac Gregor, Eduardo. La Corte Interamericana de Derechos Humanos como intérprete constitucional (dimensión trasnacional de derecho constitucional). Disponible en: <http://biblio.juridicas.unam.mx/ libros/1/94/12.pdf>.

${ }^{6}$ Hitters, Juan Carlos. "Control de Constitucionalidad y Control de Convencionalidad. Comparación”. Diario La Ley, D, 1205.
} 
Durante décadas, la jurisprudencia del máximo tribunal argentino entendió que la exigibilidad ante los tribunales nacionales de un derecho reconocido internacionalmente dependía de su tutela por las normas locales. Este criterio fue cambiando a partir del conocido precedente "Ekmekdjián cl Sofovich", pero ha sido en la última década cuando la Corte argentina ha innovado totalmente en su jurisprudencia, más precisamente en lo relativo a la aplicación de la normativa supranacional y los criterios de la Corte Interamericana. Sólo para citar algunos ejemplos, recordemos los ya célebres casos "Arancibia Clavel”, "Simón" y el controvertido caso "Mazzeo"

Las alternativas para un tribunal nacional como el argentino, puesto a dirimir la congruencia entre el artículo 27 de la Constitución y un eventual mandato de la Corte Interamericana de Derechos Humanos, cobra aún mayor relevancia si la analizamos respecto a la obligatoriedad no ya del texto de la Convención, sino a la jurisprudencia del órgano jurisdiccional del sistema interamericano de protección de derechos humanos. La indudable gravitación de la Corte nacional como poder del Estado, nos lleva a detenernos en novedosos e interesantes razonamientos formulados en disidencias planteadas en recientes fallos de la Corte Suprema de Justicia de la Nación, a partir de la aplicación de criterios de órganos supranacionales. En uno de ellos, dos de sus ministros sostuvieron que "si bien está fuera de discusión el carácter vinculante de las decisiones de la Corte Interamericana de Derechos Humanos a los efectos de resguardar las obligaciones asumidas por el Estado Argentino, aceptar que ello tenga consecuencias como las que pretende el recurrente implicaría asumir que la Corte Interamericana puede decidir sobre la responsabilidad penal de un individuo en concreto, que no ha sido parte en el proceso internacional y respecto del cual el tribunal interamericano no declaró, ni pudo declarar, su responsabilidad... En tales condiciones, una decisión como la que se pretende no sólo implicaría una afectación al derecho de defensa del imputado (que no ha estado presente ni ha sido escuchado en el proceso ante la Corte Interamericana) sino que además colocaría al Estado Argentino en la paradójica situación de cumplir con sus obligaciones internacionales a costa de una nueva afectación de derechos y garantías individuales reconocidos en la Constitución Nacional y los tratados de derechos humanos que la integran". Y enfantizan que "ello contradiría, además, la regla establecida en el artículo 29 de la Convención Americana sobre Derechos Humanos, que prohibe interpretar sus normas de modo tal que impliquen la supresión del ejercicio de los derechos por ella reconocidos o su limitación más allá de lo fijado en dicha norma internacional o, también, la limitación del goce

${ }^{7}$ CSJN, "Arancibia Clavel, Enrique Lautaro vs./homicidio calificado y asociación ilícita y otros", causa No 259 , sentencia de 24 de agosto de 2004.

${ }^{8}$ CSJN, “Simón, Julio Héctor y otros vs./privación ilegítima de la libertad, etc.”, causa No 17.768, sentencia de 14 de junio de 2005.

${ }^{9}$ CSJN, "Mazzeo, Julio Lilo y otros vs./Rec. de Casación e Inconstitucionalidad", sentencia de 13 de julio de 2007. 
y ejercicio de cualquier derecho o libertad que pueda estar reconocido de acuerdo con las leyes de un Estado"10.

El Dr. Fayt en su recordada disidencia en el caso "Simón" "11, había ya expresado que "el limite que el artículo 27 de la Constitución Nacional impone a los tratados no le impide a la Nación mantener y cultivar las relaciones de paz, amistad y comercio con las demás Naciones y ser participe del desarrollo del derecho internacional y de los diferentes procesos que se orientan a un mayor grado de interdependencia entre los Estados. Las nuevas situaciones y las nuevas necesidades de carácter internacional, no son ajenas al derecho público argentino, tanto en lo que respecta a la participación activa en la formación de los organismos internacionales como las nuevas esferas en que se mueve el derecho internacional público". El ministro subrayó que "en absoluta concordancia con el artículo 27 de la Constitución Nacional también desde la ciencia del derecho internacional se reconoce actualmente -y como ya se hiciera referencia- lo que se denomina un 'margen nacional de apreciación', doctrina nacida en la Comisión Europea de Derechos Humanos, adoptada por la Corte Europea de Derechos Humanos y recogida también por la Corte Interamericana de Derechos Humanos (conf. OC-4/84 Serie A, No 4, de 19 de enero de 1984)".

Cabe preguntarse, entonces, ¿cuál es el límite? ¿Constituyen los principios de derecho público establecidos en esta Constitución un límite presente en las decisiones del Tribunal?

Al comentar la sentencia recaída en la causa "Simón”, el Dr. Gregorio Badeni expresaba que "la lectura de la sentencia genera la percepción de que existiría en el ánimo de los jueces una decisión predeterminada cuya base de sustento no se hallaba en la Ley Fundamental. Tal circunstancia explica la omisión de toda alusión a los debates suscitados en la Convención Reformadora de 1994 sobre los alcances del artículo 75, inciso 22, de la Constitución, así como también a ciertas cláusulas de los tratados internacionales cuya aplicación conduce a resultados distintos a los adoptados por la mayoría"12.

Claro que en aquel precedente sólo el Dr. Fayt votó en disidencia, circunscribiendo su voto al texto constitucional vigente. Pero aquella idea, lejos de diluirse, pareciera hacerse presente, de momento también en disidencia, en otra reciente sentencia del máximo órgano jurisdiccional argentino. Así se ha dicho, como esbozando aquel límite sobre el que nos veníamos preguntándonos, que "la admisión de responsabilidad del Estado Argentino ante los organismos internacionales no puede acarrear como consecuencia directa la afectación de las garantías constitucionales de

\footnotetext{
${ }^{10} \mathrm{CSJN}$, “Derecho, René Jesús vs./incidente de prescripción de la acción penal”, causa № 24.079, sentencia de 29 de noviembre de 2011 (Disidencia de los Ministros Fayt y Argibay).

${ }^{11}$ CSJN, "Simón, Julio Héctor y otros vs./privación ilegítima de la libertad, etc.”, causa No 17.768, sentencia de 14 de junio de 2005.

${ }^{12}$ Badeni, Gregorio (2005). "Caso Simón y la supremacía constitucional”. Diario La Ley, Suplemento de Jurisprudencia Penal, 29 de julio, pp. 11 y ss.
} 
una persona imputada por la comisión de un delito común, quien además no ha tenido la posibilidad de ser oida en la instancia supranacional..."13.

Encontramos, entonces, en opiniones actualmente minoritarias en nuestro máximo Tribunal, fundamentos bastantes para aventurar que sí podrían esgrimirse límites ante la de las decisiones de órganos supranacionales en lo relativo a su interpretación de lo que es o no convencional, máxime cuando éstas contrariarían disposiciones no sólo de la Carta Magna nacional, sino incluso de los propios instrumentos internacionales que les han dado nacimiento. Es dable destacar, por ello, la negativa de la referida minoría a avanzar en la responsabilidad penal de un individuo por imposición de un órgano supranacional, cuando éste no ha sido oído en sede internacional, afectando el derecho de defensa del imputado.

$\mathrm{Al}$ decir de la Corte Interamericana, cada juzgador debe velar por el efecto útil de los instrumentos internacionales ${ }^{14}$. Pero si bien cada paso que se ha dado en este campo ha buscado garantizar a las personas un pleno goce y ejercicio de sus derechos individuales, este objetivo no puede conseguirse a cualquier precio en un Estado de Derecho. Precisamente al analizar la protección que el ordenamiento jurídico prevé en orden a garantizar los derechos individuales, tenemos que tener presente que "los ordenamientos jurídicos nacionales contienen principios propios que son precisamente los que le dan solidez y autonomía. Actúan como fuente supletoria en caso de ausencia de normas e integran el derecho; informan e inspiran al legislador, orientan al juez y al intérprete y fundamentan el orden jurídico. En suma, son la esencia de los respectivos derechos" 15 . Una decisión encaminada a consagrar la solución propuesta en los precedentes "Castañeda" y "Derecho" por la minoría de la Corte configuraría, a nuestro criterio, una necesaria reafirmación de los límites por los cuales el fiel acatamiento a las decisiones de órganos supranacionales, definitivamente, no puede acarrear como consecuencia directa la afectación de las garantías constitucionales.

${ }^{13}$ CSJN, disidencia de los ministros Fayt y Argibay, "Castañeda, Carlos Antonio vs./sustracción y destrucción de medios de prueba", causa No 768 .

${ }^{14}$ Corte IDH, "Caso Heliodoro Portugal Vs. Panamá. Excepciones Preliminares, Fondo, Reparaciones y Costas", sentencia de 12 de agosto de 2008.

${ }^{15}$ Dreyzin, Adriana. "El orden público internacional en el área del derecho internacional privado". Anuario CIJS, No 6, sección 2: Derecho internacional privado e integración regional, Centro de Investigaciones Jurídicas y Sociales, Facultad de Derecho y Ciencias Sociales, Universidad Nacional de Córdoba, p. 242. Disponible en: <http://biblioteca.clacso.edu.ar//Argentina/cijs-unc/20110807070544/sec6002b.pdf>. 